
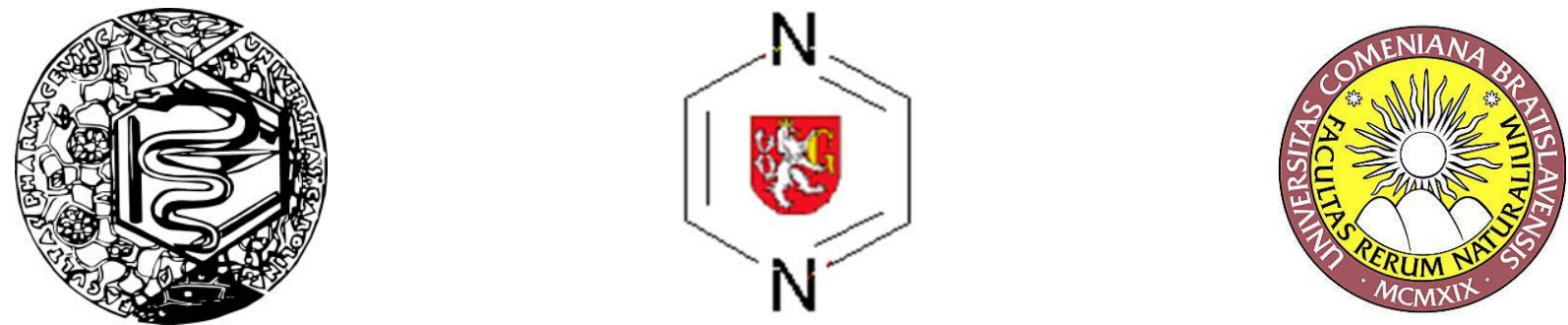

\title{
New potentially active pyrazinamide derivatives synthesized under microwave conditions
}

\section{Ondrej JANDOUREK ${ }^{1 *}$, Martin DOLEZAL ${ }^{1}$, Matus PESKO²,}

\section{Vladimir KUBICEK ${ }^{1}$, Katarina KRALOVA ${ }^{2}$}

1 Faculty of Pharmacy in Hradec Kralove, Charles University, Heyrovskeho 1203, 50005 Hradec

Kralove, Czech Republic

2 Faculty of Natural Sciences, Comenius University, Mlynska Dolina CH-2, 84215 Bratislava, Slovakia

* Corresponding author

\section{ABSTRACT}

A series of $18 \mathrm{~N}$-alkyl substituted 3-aminopyrazine-2-carboxamides was prepared in the work for this contribution. All these substances were prepared according to previously experimentally set and proven conditions using the methodology of microwave assisted synthesis. This approach for the aminodehalogenation reaction was chosen due to higher yields and shorter reaction times. Compounds were put to the evaluation of their antibacterial, antifungal and herbicidal properties.

Only a small number of substances showed activity against fungi which was the same or higher than standards. They were namely the compounds with alicyclic side chain. The biological efficacy of the compounds was increasing with rising lipophilicity. The same relationship can be found for the herbicidal activities. These compounds also inhibited photosynthetic electron transport in spinach chloroplasts and the $\mathrm{IC}_{50}$ values of the most active compounds varied in the range from 14.3 to 1590 $\mu \mathrm{mol} / \mathrm{L}$. The inhibitory activity was connected not only with the lipophilicity but also with the presence of secondary amine fragment bounded to the pyrazine ring. Structure-activity relationships are discussed as well.

\section{KEYWORDS}

Aminodehalogenation, Antifungal activity, Herbicidal activity, Microwave assisted synthesis, Pyrazinamide, SAR 


\section{INTRODUCTION}

Pyrazinamide (PZA) is counted among the most important molecules in the world. It has got numerous ways of use and pyrazine ring is contained in many natural structures at the same time. Nevertheless, the main field of use is still the treatment of tuberculosis. PZA is classified as the firstline antituberculotic agent that is unique for its therapeutic properties. It acts in acidic environment as a bactericidal sterilising drug that is able to kill the dormant forms of tubercle bacilli. These so called persistors are just situated in nidus where the acidic $\mathrm{pH}$ is typical [1].

On the contrary, the mechanism of action is still under the investigation of researchers all over the world. One of the first theories suggested that it is necessary to activate PZA via enzyme pyrazinamidase (nicotinamidase) to its active form pyrazinecarboxylic acid. This molecule gets into the mycobacterial cell and causes the inner cell compartment acidification in the train of the ionic efflux. These consequences lead to cellular death $[2,3]$.

Another theory propounded the inhibition of fatty acid synthase I (FAS I). This is the enzyme necessary for synthesis of mycolic acids, which are essential for mycobacterial cell wall composition. Despite the fact that PZA is effective, this mechanism of action was confirmed only for 5chloropyrazinamide and its derivatives [4].

The last known theory was introduced by Zhang et al. and proposed the inhibition of transtranslation as the main way of action of PZA. This cellular process is essential for survival and virulence of Mycobacteria. All these hypotheses were supported with in vitro experiments [5].

PZA and its derivatives have got also a few other applications. These compounds showed antifungal, antibacterial and as well as antineoplastic activities [6-12]. Several pyrazine derivatives were also found to inhibit photosynthetic electron transport (PET) in plant chloroplasts [13, 14 and 15]. Using EPR spectroscopy as the site of action of pyrazine-derived PET inhibitors intermediate $D^{\bullet}$ i.e. tyrosine radical $\left(\operatorname{Tyr}_{\mathrm{D}}{ }^{\circ}\right)$ situated in the 161st position in $\mathrm{D}_{2}$ protein on the donor side of photosystem (PS) 2 was determined [16, 17]. The photosynthetic electron transport between PS 2 and PS 1 was interrupted due to this interaction, while the primary donor of PS 2 (P680) remained intact. Similar site of action in the photosynthetic apparatus of spinach chloroplasts was confirmed for 2alkylsulfanylpyridine-4-carbothioamides [18] and substituted benzanilides and thiobenzanilides [19]. Many structural variations of pyrazine compounds with herbicidal properties can be found in the patent literature focused on compounds with herbicidal activity that are useful for the control of unwanted vegetation $[20,21]$.

One more aspect of this work is the usage of microwave assisted reaction. It is known, that microwave assisted syntheses have become into general awareness during the last decades and the ways of application are still in scope of researchers. Why has it turned into so popular issue? The answer is self-evident. There are usually higher yields, shorter reaction times, and better chemical conversions in comparison with conventional organic chemistry methods and sometimes the desired products can be obtained only by using the microwaves accelerated reactions [22]. Also, there should be less emerging side-products and if they are detected, they can be eliminated by many separation methods such as chromatography or crystallization. The advantages of these reactions are explained by interaction between microwaves and molecules themselves neither vessel sides nor solvents. And 
there is possibility of reaching higher temperatures then the boiling point of solvent is, especially in over pressurized systems. So a new way has been opened for drug discovery and development [23].

In this study, we focused on the synthesis of pyrazine derivatives with aliphatic or alicyclic side chain and their antibacterial, antifungal and PET-inhibiting activities.

\section{METHODS AND EXPERIMENTAL}

All the chemicals, which were used for starting compound preparation and for aminodehalogenation reactions, were reagent or higher grade of purity and were purchased from Sigma-Aldrich and Fluorochem Ltd.

Starting compound was prepared according to proven methodology of conventional organic synthesis. The final aminodehalogenation reaction was performed in microwave reactor with focused field CEM Discover (CEM Corporation, Matthews, North Carolina, USA) connected to autosampler Explorer 24 (CEM Corporation, Matthews, North Carolina, USA) and this equipment was running under CEM's Synergy ${ }^{\mathrm{TM}}$ software for monitoring the progress of reactions. The success of the reaction was checked by Thin Layer Chromatography (TLC) (Alugram ${ }^{\circledR}$ Sil G/UV ${ }_{254}$, Machery-Nagel, Postfach, Germany) with UV detection using wavelength $254 \mathrm{~nm}$.

All the obtained products were purified by crystallization or by preparative flash chromatograph CombiFlash $^{\circledast}$ Rf (Teledyne Isco Inc., Lincoln, Nebraska, USA). The gradient elution was practised making use of hexane (Lachema, CZ) and ethyl acetate (Penta, CZ) as mobile phases. Silica gel $(0.040$ $-0.063 \mathrm{~nm}$, Merck, Germany) was used as the stationary phase.

NMR spectra were taken with spectrometers Varian Mercury - VxBB 300 with frequencies 299.95 $\mathrm{MHz}$ for ${ }^{1} \mathrm{H}$ and $75.43 \mathrm{MHz}$ for ${ }^{13} \mathrm{C}$ or Varian Mercury - VxBB 500 with frequencies $499.87 \mathrm{MHz}$ for ${ }^{1} \mathrm{H}$ and $125.71 \mathrm{MHz}$ for ${ }^{13} \mathrm{C}$ (Varian Corporation, Palo Alto, California, USA). Chemical shifts were reported in ppm $(\delta)$ and were applied indirectly to tetramethylsilane as a signal of solvent (2.49 for ${ }^{1} \mathrm{H}$ and 39.7 for ${ }^{13} \mathrm{C}$ in DMSO- $d_{6}$ ). Infrared spectra were recorded with spectrometer FT-IR Nicolet 6700 (Nicolet-Thermo Scientific, USA) using attenuated total reflectance (ATR) methodology. Melting points were assessed by SMP3 Stuart Scientific (Bibby Sterling Ltd., UK) and were uncorrected. Elemental analyses were measured with EA 1110 CHNS Analyzer (Fisons Instruments S. p. A., Carlo Erba, Milano, Italy). Log $P$ and Clog $P$ were calculated with PC programme CS ChemBioDraw Ultra 13.0 (CambridgeSoft, Cambridge, Massachusetts, USA).

Experimental lipophilicity parameter log $k$ was ascertained using HPLC system. Agilent Technologies 1200 SL liquid chromatography with Diode-array Detector SL G1315C, chromatographic pre-column ZORBAX XDB-C18 $5 \mu \mathrm{m}, 4 \times 4$ mm, Part No. 7995118-504 and column ZORBAX Eclipse XDB-C18 $5 \mu \mathrm{m}$, $4.6 \times 250$ mm, Part No. 7995118-585 (Agilent Technologies Inc., Colorado Springs, CO, USA) were used. The separation process was controlled by Agilent ChemStation, version B.04.02 extended by spectral module (Agilent Technologies Inc.). A solution of $\mathrm{MeOH}$ (HPLC grade, $70 \%$ ) and $\mathrm{H}_{2} \mathrm{O}$ (HPLCMilli-Q Grade, $30 \%$ ) was used as mobile phase. The total flow of the column was $1.0 \mathrm{~mL} / \mathrm{min}$, injection $20 \mu \mathrm{L}$, column temperature $30^{\circ} \mathrm{C} .210 \mathrm{~nm}$ as detection wavelength and $270 \mathrm{~nm}$ as monitor wavelength were chosen. The $\mathrm{KI}$ methanol solution was used for the dead time $\left(T_{\mathrm{D}}\right)$ determination. Retention times $\left(T_{R}\right)$ of synthesized compounds were measured in minutes. The capacity factors $k$ 
were calculated using Microsoft Excel according to formula $k=\left(T_{R}-T_{D}\right) / T_{D}$, where $T_{R}$ is the retention time of the solute and $T_{D}$ denotes the dead time obtained via an unretained analyte. Log $k$, calculated from the capacity factor $k$, is used as the lipophilicity index converted to $\log P$ scale.

Antibacterial evaluation was made using the microdilution broth method in plates M27A-M1 $(200+10)$ against 8 bacterial stems from Czech Collection of Microorganisms (Brno, CZ) or clinical isolates from Department of Clinical Microbiology, University Hospital in Hradec Kralove (Hradec Kralove, CZ) (Staphylococcus aureus CCM 4516/08, Staphylococcus aureus H 5996/08 methicillin resistant, Staphylococcus epidermidis H 6966/08, Enterococcus sp. J14365/08, Escherichia coli CCM 4517, Klebsiella pneumoniae D 11750/08 , Klebsiella pneumoniae J 14368/05 ESBL positive, Pseudomonas aeruginosa CCM 1961). Mueller Hinton broth was used for the cultivation that was done in humid atmosphere and $35^{\circ} \mathrm{C}$. The readings were made after 24 and 48 hours and MIC was set as $80 \%$ inhibition of control. The standards were neomycin, bacitracin, penicillin $\mathrm{G}$, ciprofloxacin and phenoxymethylpenicillin [24].

Antifungal evaluation was also accomplished with microdilution broth method. On the contrary, there was used RPMI 1640 broth with glutamine as medium and conditions were humid and dark atmosphere, $\mathrm{pH} 7.0$ and $35^{\circ} \mathrm{C}$. 8 fungal strains were used (Candida albicans ATCC 44859, Candida tropicalis 156, Candida krusei E28, Candida glabrata 20/I, Trichosporon asahii 1188, Aspergillus fumigatus 231, Absidia corymbifera 272, Trichophyton mentagrophytes 445) together with 4 antimycotic standards amphotericin B, voriconazole, nystatin and fluconazole. The MIC was set as $80 \%$ inhibition of control and readings were made after 24 and 48 hours (50\% IC, 72 and 120 hours for fibrous fungi) [25].

The inhibition of photosynthetic electron transport (PET) in spinach chloroplasts was determined spectrophotometrically (Genesys 6, Thermo Scientific, USA) using an artificial electron acceptor 2,6dichlorophenol-indophenol (DCPIP) [26]. The rate of photosynthetic electron transport was monitored as a photoreduction of DCPIP. Chloroplasts were prepared from Spinacia oleracea L. [27]. The measurements were carried out in phosphate buffer $(0.02 \mathrm{~mol} / \mathrm{L}, \mathrm{pH} 7.2)$ containing sucrose $(0.4$ $\mathrm{mol} / \mathrm{L}), \mathrm{MgCl}_{2}(0.005 \mathrm{~mol} / \mathrm{L})$ and $\mathrm{NaCl}(0.015 \mathrm{~mol} / \mathrm{L})$. The chlorophyll concentration was $30 \mathrm{mg} / \mathrm{L}$ and the samples were irradiated with a halogen lamp (250W). The $4 \mathrm{~cm}$ wide water filter was used to prevent warming of the suspension and temperature of it did not exceed $22^{\circ} \mathrm{C}$. The efficiency of studied compounds was expressed as $50 \%$ inhibition concentration relative to the untreated control. The standard for these measurements was DCMU (Diurone ${ }^{\circledR}$ ). The emission fluorescence spectra of aromatic amino acids were recorded on the fluorescence spectrophotometer F-2000 (Hitachi, Tokyo, Japan). The samples of chloroplast suspensions with and without studied inhibitor were excited at wavelength of $275 \mathrm{~nm}$, excitation slit $20 \mathrm{~nm}$ and emission slit $10 \mathrm{~nm}$. The samples were kept in the dark for 2 minutes prior to the measurement. The phosphate buffer used for dilution of the chloroplast suspension was the same as described above. The compounds were added to chloroplast suspension in DMSO solution due to low aqueous solubility. The DMSO concentration in all samples was the same as in the control (10\%). The chlorophyll concentration in chloroplast suspension was 10 $\mathrm{mg} / \mathrm{L}$. 


\section{RESULTS AND DISCUSSION}

Starting compound 3-chloropyrazine-2-carboxamide was synthesised according to proven procedure, when 3-chloropyrazine-2-carbonitrile was put to partial hydrolysis of nitrile group. The powdered carbonitrile was added little by little into the reaction mixture of hydrogen peroxide and water. $\mathrm{pH}$ was adjusted and regulated about the value of 9 using $8 \%$ solution of sodium hydroxide and the temperature was regulated between 55 and $60^{\circ} \mathrm{C}$. The reaction was stopped after 2 and half hours and cooled to $5{ }^{\circ} \mathrm{C}$. Newly-emerged crystals were removed by suction and recrystallized from ethanol. The identity and purity were proven by NMR spectra and melting point [28]. 3Chloropyrazine-2-carboxamide was then treated with 18 aliphatic, alicyclic amines and saturated heterocycles containing nitrogen. There was done a series of experiments in the beginning to compare the efficiency of both methods - conventional and microwave-assisted (Tab. 1).

Tab. 1 - Table comparing the efficiency of conventional and microwave-assisted methodology showing the yields and reaction times

\begin{tabular}{|c|c|c|c|c|c|c|}
\hline \multicolumn{2}{|r|}{ Compound } & \multirow{2}{*}{$\begin{array}{c}\text { Type of synthesis } \\
\text { MW }\end{array}$} & \multirow{2}{*}{$\frac{\text { Time }}{30 \mathrm{~min}}$} & \multirow{2}{*}{$\begin{array}{c}\text { Conditions } \\
140^{\circ} \mathrm{C}, 120 \mathrm{~W}, \mathrm{MeOH}, \\
\text { pyridine, overpressure }\end{array}$} & \multicolumn{2}{|c|}{ Yield } \\
\hline \multirow{2}{*}{1} & & & & & $118,5 \mathrm{mg}$ & $61,4 \%$ \\
\hline & & Conventional & $60 \mathrm{~min}$ & $110^{\circ} \mathrm{C}$, toluene, pyridine & $102,3 \mathrm{mg}$ & $53,0 \%$ \\
\hline \multirow{2}{*}{2} & & $\mathrm{MW}$ & $30 \mathrm{~min}$ & $\begin{array}{l}140^{\circ} \mathrm{C}, 120 \mathrm{~W}, \mathrm{MeOH}, \\
\text { pyridine, overpressure }\end{array}$ & $166,0 \mathrm{mg}$ & $78,7 \%$ \\
\hline & & Conventional & $60 \mathrm{~min}$ & $110^{\circ} \mathrm{C}$, toluene, pyridine & $97,6 \mathrm{mg}$ & $46,3 \%$ \\
\hline \multirow{2}{*}{3} & & MW & $30 \mathrm{~min}$ & $\begin{array}{l}140^{\circ} \mathrm{C}, 120 \mathrm{~W}, \mathrm{MeOH}, \\
\text { pyridine, overpressure }\end{array}$ & $199,0 \mathrm{mg}$ & $87,0 \%$ \\
\hline & & Conventional & $60 \mathrm{~min}$ & $110^{\circ} \mathrm{C}$, toluene, pyridine & $128,3 \mathrm{mg}$ & $56,1 \%$ \\
\hline \multirow{2}{*}{10} & & $\mathrm{MW}$ & $30 \mathrm{~min}$ & $\begin{array}{l}140^{\circ} \mathrm{C}, 120 \mathrm{~W}, \mathrm{MeOH}, \\
\text { pyridine, overpressure }\end{array}$ & $213,5 \mathrm{mg}$ & $67,2 \%$ \\
\hline & & Conventional & $60 \mathrm{~min}$ & $110^{\circ} \mathrm{C}$, toluene, pyridine & $0 \mathrm{mg}$ & $0 \%$ \\
\hline
\end{tabular}

Then the rest of reactions took place in microwave reactor and the conditions, which were proven experimentally, were as follows: $140{ }^{\circ} \mathrm{C}, 30 \mathrm{~min}, 120 \mathrm{~W}$, methanol as a solvent and pyridine as a base (Fig. 1). 
<smiles>N#Cc1nccnc1Cl</smiles><smiles>[R]Nc1ncc(C(N)=O)nc1C(N)=O</smiles>

$\mathrm{R}$ - aliphatic, alicyclic amines and saturated heterocycles containing nitrogen $\mathrm{MW}$ - microwaves; $150^{\circ} \mathrm{C}, 30 \mathrm{~min}, 120 \mathrm{~W}$, methanol, pyridine

Fig. 1 - Synthesis of starting compound and microwave assisted synthesis of final compounds

This reaction yielded $\mathrm{N}$-substituted 3-aminopyrazine-2-carboxamides (Tab. 2). The prepared series was consisted of 18 compounds that were chemically characterized (NMR and IR spectra, melting point, elemental analysis) and put to biological evaluations.

Tab. 2 - List of prepared compounds and their lipophilicity

\begin{tabular}{|c|c|c|c|c|}
\hline Nr. & Name & $\mathbf{R}$ & $\log P / C \log P$ & $\log k$ \\
\hline 1 & 3-(methylamino)pyrazine-2-carboxamide & $-\mathrm{CH}_{3}$ & $-1.10 / 0.20$ & -0.4028 \\
\hline 2 & 3-(ethylamino)pyrazine-2-carboxamide & $-\mathrm{C}_{2} \mathrm{H}_{5}$ & $-0.76 / 0.73$ & -0.2014 \\
\hline 3 & 3-(propylamino)pyrazine-2-carboxamide & $-\mathrm{C}_{3} \mathrm{H}_{7}$ & $-0.27 / 1.25$ & 0.0038 \\
\hline 4 & 3-(butylamino)pyrazine-2-carboxamide & $-\mathrm{C}_{4} \mathrm{H}_{9}$ & $0.14 / 1.78$ & 0.2287 \\
\hline 5 & 3-(pentylamino)pyrazine-2-carboxamide & $-\mathrm{C}_{5} \mathrm{H}_{11}$ & $0.56 / 2.31$ & 0.4564 \\
\hline 6 & 3-(tert-pentylamino)pyrazine-2-carboxamide & $-\mathrm{C}_{5} \mathrm{H}_{11}$ & $0.26 / 1.96$ & 0.5468 \\
\hline 7 & 3-(hexylamino)pyrazine-2-carboxamide & $-\mathrm{C}_{6} \mathrm{H}_{13}$ & $0.98 / 2.84$ & 0.6860 \\
\hline 8 & 3-(heptylamino)pyrazine-2-carboxamide & $-\mathrm{C}_{7} \mathrm{H}_{15}$ & $1.40 / 3.37$ & 0.9198 \\
\hline 9 & 3-(octylamino)pyrazine-2-carboxamide & $-\mathrm{C}_{8} \mathrm{H}_{17}$ & $1.81 / 3.90$ & 1.1533 \\
\hline 10 & 3-(dibutylamino)pyrazine-2-carboxamide & $-\left(\mathrm{C}_{4} \mathrm{H}_{9}\right)_{2}$ & $2.17 / 3.40$ & 0.5197 \\
\hline 11 & 3-(cyclopentylamino)pyrazine-2-carboxamide & - cyclo- $\mathrm{C}_{5} \mathrm{H}_{9}$ & $0.03 / 1.67$ & 0.2537 \\
\hline 12 & 3-(cyclohexylamino)pyrazine-2-carboxamide & - cyclo- $\mathrm{C}_{6} \mathrm{H}_{11}$ & $0.45 / 2.23$ & 0.4523 \\
\hline 13 & 3-(cycloheptylamino)pyrazine-2-carboxamide & - cyclo- $\mathrm{C}_{7} \mathrm{H}_{13}$ & $0.87 / 2.79$ & 0.6575 \\
\hline 14 & 3-(pyrrolidin-1-yl)pyrazine-2-carboxamide & $-\mathrm{C}_{4} \mathrm{H}_{8} \mathrm{~N}$ & $0.01 / 0.34$ & -0.4889 \\
\hline 15 & 3-(piperidin-1-yl)pyrazine-2-carboxamide & $-\mathrm{C}_{5} \mathrm{H}_{10} \mathrm{~N}$ & $0.42 / 0.90$ & -0.2333 \\
\hline 16 & 3-morpholinopyrazine-2-carboxamide & $-\mathrm{C}_{4} \mathrm{H}_{8} \mathrm{NO}$ & $-0.71 /-0.49$ & -0.6238 \\
\hline 17 & 3-(4-methylpiperazin-1-yl)pyrazine-2-carboxamide & $-\mathrm{C}_{4} \mathrm{H}_{8} \mathrm{~N}_{2} \mathrm{CH}_{3}$ & $-0.55 / 0.08$ & -0.4253 \\
\hline 18 & 3-(piperazin-1-yl)pyrazine-2-carboxamide & $-\mathrm{C}_{4} \mathrm{H}_{9} \mathrm{~N}_{2}$ & $-0.93 /-0.50$ & -2.3522 \\
\hline
\end{tabular}


The dependence of experimentally determined $\log k$ on calculated $\log P$ values of tested compounds is shown in Fig. 2. While for compounds 1-17 linear dependence of $\log k$ on $\log P$ was determined $(r=$ 0.816), the estimated log $k$ value for 3-(piperazin-1-yl)pyrazine-2-carboxamide (18) was considerably lower than expected. This could be connected with the presence of secondary cyclic amine that can be very easily ionized.

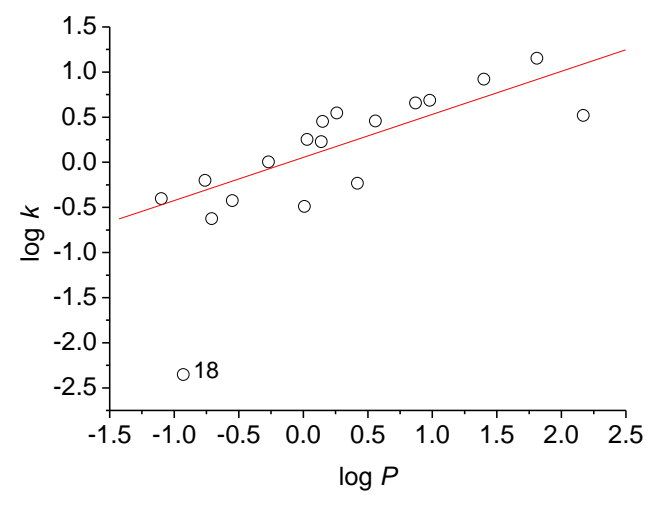

Fig. 2 - Dependence of experimentally determined $\log k$ on calculated $\log P$ values of tested compounds.

The results of antibacterial screening have shown only low activities against Staphylococcus epidermidis. Antibacterial activity that was not better than $250 \mu \mathrm{mol} / \mathrm{L}$ and did not reach the values of antibiotic standards was observed for compounds 5, 7 and 13.

Antifungal evaluation showed more interesting results. There were seven active substances and 2 of them (12 and 13) had better activity values than 2 standards (voriconazole, fluconazole)(Tab. 3). The alicyclic side chain with 7 carbons was more active than the 6 membered ring. The $80 \%$ inhibition of control was observed in the range from 250 to $15.62 \mu \mathrm{mol} / \mathrm{L}$ for compound 12 and in the range from 125 to $7.81 \mu \mathrm{mol} / \mathrm{L}$ for compound $\mathbf{1 3}$ against whole spectrum of fungi tested after 24 hours of incubation. Other five substances $(\mathbf{4}, \mathbf{5}, \mathbf{7}, \mathbf{8}$ and $\mathbf{1 1})$ were less active than standards and the values were not better than $250 \mu \mathrm{mol} / \mathrm{L}$. The activity spectrum of these compounds was also wider and did not include only one stem.

Due to small number of active substances and a lack of values better than standards it is not possible to predict structure-activity relationships for antibacterial and antifungal efficacy of studied compounds in whole group. However, saturated ring is probably important for antifungal activity and the activity also grows with increasing lipophilicity. But the series is too small (only 3 compounds) to prove this hypothesis. 
Tab. 3 - Results of antifungal evaluation for the compounds with alicyclic side chains

\begin{tabular}{|c|c|c|c|c|c|c|c|c|}
\hline & & 11 & 12 & 13 & AMP & VOR & NYS & FLU \\
\hline \multirow{2}{*}{ CA } & $24 \mathrm{~h}$ & 500 & 31,25 & 15,62 & 0,12 & 0,008 & 0,98 & 0,24 \\
\hline & $48 \mathrm{~h}$ & $>500$ & 62,5 & 31,25 & 0,49 & 0,008 & 1,95 & 0,24 \\
\hline \multirow{2}{*}{ CT } & $24 \mathrm{~h}$ & $>500$ & 125 & 62,5 & 1,95 & 250 & 1,95 & $>500$ \\
\hline & $48 \mathrm{~h}$ & $>500$ & 500 & 500 & 1,95 & 250 & 3,9 & $>500$ \\
\hline \multirow{2}{*}{ CK } & $24 \mathrm{~h}$ & 250 & 15,62 & 7,81 & 1,95 & 0,98 & 1,95 & 125 \\
\hline & $48 \mathrm{~h}$ & 500 & 62,5 & 31,25 & 1,95 & 1,95 & 3,9 & 250 \\
\hline \multirow{2}{*}{ CG } & $24 \mathrm{~h}$ & 250 & 15,62 & 7,81 & 0,98 & 250 & 1,95 & 31,25 \\
\hline & $48 \mathrm{~h}$ & $>500$ & 31,25 & 15,62 & 1,95 & 250 & 3,9 & 250 \\
\hline \multirow{2}{*}{ TA } & $24 \mathrm{~h}$ & 500 & 31,25 & 31,25 & 0,49 & 7,81 & 1,95 & 250 \\
\hline & $48 \mathrm{~h}$ & $>500$ & 250 & 125 & 0,98 & 31,25 & 1,95 & 500 \\
\hline \multirow{2}{*}{ AF } & $24 \mathrm{~h}$ & 500 & 15,62 & 7,81 & 1,95 & 0,49 & 1,95 & $>500$ \\
\hline & $48 \mathrm{~h}$ & $>500$ & 62,5 & 7,81 & 1,95 & 0,98 & 3,9 & $>500$ \\
\hline \multirow{2}{*}{$A C$} & $24 \mathrm{~h}$ & $>500$ & 250 & 62,5 & 7,81 & 250 & 15,62 & $>500$ \\
\hline & $48 \mathrm{~h}$ & $>500$ & 500 & 250 & 7,81 & 250 & 31,25 & $>500$ \\
\hline \multirow{2}{*}{ TM } & $72 \mathrm{~h}$ & 500 & 15,62 & 15,62 & 1,95 & 0,06 & 3,9 & 7,81 \\
\hline & $120 \mathrm{~h}$ & 500 & 15,62 & 15,62 & 1,95 & 0,12 & 7,81 & 125 \\
\hline
\end{tabular}

CA - Candida albicans, CT - C. tropicalis, CK - C. krusei, CG - C. glabrata, TA - Trichosporon asahii, AF - Aspergillus fumigatus, AC - Absidia corymbifera, TM - Trichophyton mentagrophytes, AMP - amphotericin B, VOR - voriconazole, NYS - nystatin, FLU - fluconazole; concentrations stated in $\mu \mathrm{mol} / \mathrm{L}$

Nine of tested compounds were found to inhibit PET in spinach chloroplasts (Tab. 4). The PETinhibiting activity, expressed by $\mathrm{IC}_{50}$ value (compound concentration in $\mathrm{mol} / \mathrm{L}$ causing $50 \%$ inhibition of PET) in the investigated set varied from $14.3 \mu \mathrm{mol} / \mathrm{L}$ (9) to $1590 \mu \mathrm{mol} / \mathrm{L}(3)$. On the other hand, very low activity of compounds $1,2,10,14,15,16,17$, and 18 did not allow determining $I_{50}$ values related to PET inhibition.

Tab. $4-I C_{50}$ values $[\mu \mathrm{mol} / \mathrm{L}]$ of tested compounds related to PET inhibition in spinach chloroplasts in comparison with 3-(3,4-dichlorophenyl)-1,1- dimethylurea (DCMU) standard.

\begin{tabular}{|c|c|}
\hline Compound & $\mathrm{IC}_{50}[\mu \mathrm{mol} / \mathrm{L}]$ \\
\hline $\mathbf{3}$ & 1590 \\
\hline $\mathbf{4}$ & 203 \\
\hline $\mathbf{5}$ & 38.6 \\
\hline $\mathbf{6}$ & 480 \\
\hline $\mathbf{7}$ & 32.9 \\
\hline $\mathbf{9}$ & 14.3 \\
\hline $\mathbf{1 1}$ & 25.8 \\
\hline $\mathbf{1 2}$ & 83.0 \\
\hline $\mathbf{1 3}$ & 19.3 \\
\hline DCMU & 1.9 \\
\hline
\end{tabular}

The PET-inhibiting activity was strongly affected by lipophilicity of the compounds (Fig. $\mathbf{3}$ ) expressed as $\log P$ or $\log k$. The PET-inhibiting activity increased with increasing lipophilicity of the compound and the dependence of $\log \left(1 / I_{50}\right)$ vs $\log P$ showed quasi-parabolic course (Fig. 3A). The only 
exception was compound $11(R=$ cyclopentyl) with $\log P=0.03$, activity of which was considerably higher $\left(I C_{50}=25.8 \mu \mathrm{mol} / \mathrm{L}\right)$ than that of compound 4 with $\log P=0.14\left(I_{50}=203 \mu \mathrm{mol} / \mathrm{L}\right)$. Similarly, quasi-parabolic course was also observed for the dependence of PET inhibiting activity on log $k$. However, with respect to the quasi-parabolic course of this dependence, compound $\mathbf{1 1}$ ( $\log k=$ 0.2537) showed higher and compound 6 ( $\log k=0.5468$ ) lower PET inhibiting activity (Fig. 3B).

The obtained results indicated that $\mathrm{IC}_{50}$ could not be determined for compounds with too low lipophilicity, namely 1 ( $\log P=-1.3), 2$ ( $\log P=-0.76)$ or for compounds with adverse steric arrangement of $R$ substituent $\left(\mathbf{1 0}, R=\left(\mathrm{C}_{4} \mathrm{H}_{9}\right)_{2}\right)$. However, ineffectiveness of compound $\mathbf{1 0}$ could be also connected with absence of secondary amine fragment (-NH-) bound to pyrazine ring, which was substituted by $\mathrm{C}_{4} \mathrm{H}_{9}$ alkyl chain. Similarly, among the other inactive compounds $14,15,16,17$ and 18 such this fragment did not occur. This limited possible interactions of these compounds with constituents of photosynthetic apparatus. On the other hand, $\mathrm{CONH}_{2}$ group plays an important role in interactions of tested pyrazine derivatives with constituents of photosynthetic apparatus. Moreover, increasing length of the alkyl substituent contributes not only to better transport of the compound to its site of action but incorporation of longer alkyl chains into thylakoid membrane results in membrane damage and consecutive increase of PET inhibiting activity. Similar results were also obtained with 2-alkylthio-4-pyridinecarbothioamides [18].
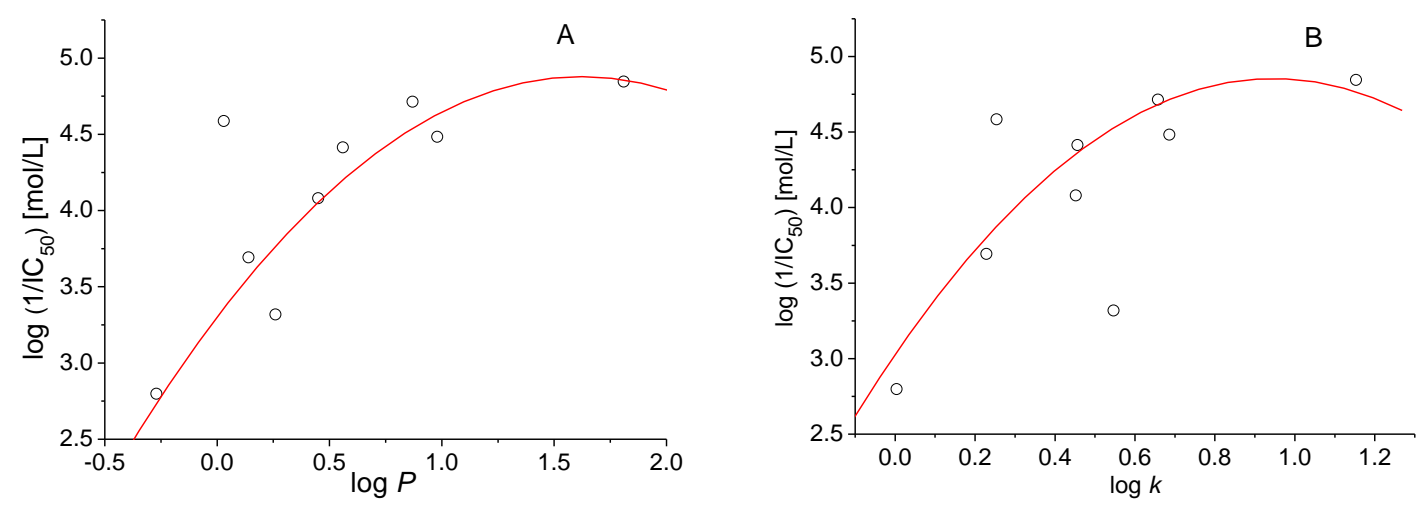

Fig. 3 - Dependence of PET-inhibiting activity on lipophilicity of studied compounds expressed as $\log P(\mathrm{~A}) \operatorname{or} \log k(\mathrm{~B})$

Application of an artificial electron donor 2,5-diphenylcarbazide (DPC) acting in $Z^{\circ} / D^{\circ}$ intermediate to chloroplasts activity of which was inhibited by the studied compounds was used to specify their site of inhibitory action. Because after the DPC addition practically complete restoration of PET was observed it can be concluded that the site of action of tested compounds in the electron transport chain is situated exclusively on the donor side of PS 2 , between oxygen evolving complex and $Z^{\circ} / \mathrm{D}^{\circ}$ intermediate, while the section of the electron transport chain on the acceptor side of PS2 between $\mathrm{P} 680$ and secondary quinone acceptor $\mathrm{Q}_{\mathrm{B}}$ is not damaged.

Interaction of studied compounds with aromatic amino acids, which are present in proteins of spinach chloroplasts situated in PS 2, was documented by the quenching of their fluorescence at 334 nm. Fig. 4 presents fluorescence emission spectra of aromatic amino acids of untreated spinach chloroplasts and of chloroplasts treated with increasing concentrations of compound 7 . As shown in 
Fig. 4, the quenching of the fluorescence of aromatic amino acids at $334 \mathrm{~nm}$ increased with increasing concentration of pyrazine derivative. Binding of studied compounds to aromatic amino acids occurring in photosynthetic proteins contributed to PET inhibition.

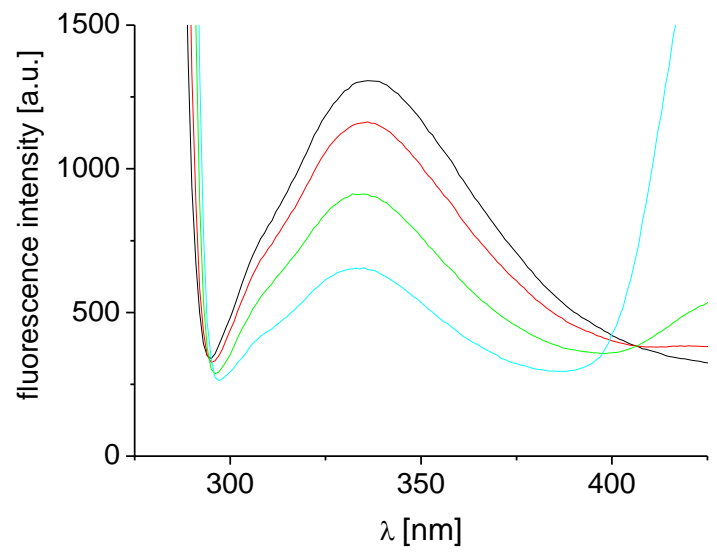

Fig. 4 - Fluorescence emission spectra of aromatic amino acids in suspension of spinach chloroplasts without and with compound 7 ( $c=0,6,24$ and $48 \mu \mathrm{mol} / \mathrm{L}$; the curves from top to bottom); excitation wave length $\lambda=275 \mathrm{~nm}$; chlorophyll concentration $10 \mathrm{mg} / \mathrm{L}$.

\section{CONCLUSIONS}

Eighteen 3-aminopyrazine-2-carboxamides were synthesized in this work with the application of microwave technology with focused field. The experimentally set conditions lead to higher yields and shorter reaction times. All the compounds were purificated and then their structure was confirmed by NMR and IR spectra.

Although there were not enough active compounds in antibacterial and antifungal screenings, we can suggest a hypothesis that the side alicyclic chain is necessary for antifungal activity and that the efficacy rises with growing number of carbons i.e. increasing lipophilicity.

PET inhibition screening showed some interesting consequences. There were 9 compounds active and activity of the most active substance was $14.3 \mu \mathrm{mol} / \mathrm{L}$. It was only 7.5 times lower than the standard DCMU $(1.9 \mu \mathrm{mol} / \mathrm{L})$. We can also say that the efficacy was affected by lipophilicity of the compounds. It is similar to the antifungal activities. The dependence of herbicidal activity on the lipophilic properties of substituents was quasi-parabolic. We can expect that longer side chain would lead to lower activities. So the optimal length is about 7 or 8 carbons. These active compounds were found to be PS 2 inhibitors acting on the donor side of photosystem 2 .

Based on obtained results it can be concluded that the biological activity of the compounds is affected by the presence of secondary amine group bounded to pyrazine ring. If this - $\mathrm{NH}$ - fragment is missing, the efficacy would also disappear. This phenomenon can be seen in both evaluations. 


\section{ACKNOWLEDGEMENTS}

The publication is co-financed by the European Social Fund and the state budget of the Czech Republic. Project no. CZ.1.07/2.3.00/20.0235, the title of the project: TEAB. This study was also supported by the Ministry of Health of Czech Republic (IGA NZ 13346), Grant Agency of Charles University B-CH/710312, the Slovak Grant Agency VEGA (grant No. 1/0612/11) and by Sanofi-Aventis Pharma Slovakia.

\section{REFERENCES}

[1] LIMA, C. H. S., BISPO, M. L. F., DE SOUZA, M. V. N. Pirazinamida: Um Fàrmaco Essencial no Tratamento da Tuberculose. Rev. Virtual Quim., 2011, 3 (3), 159-180.

[2] ZHANG, Y., WADE, M. M., SCORPIO, A. Mode of action of pyrazinamide: disruption of Mycobacterium tuberculosis membrane transport and energetics by pyrazinoic acid. J. Antimicrob. Chemoth., 2003, 52 (5), 790. ISSN 03057453.

[3] ZHANG, Y., SCORPIO, A., NIKAIDO, H., SUN, Z. J. Role of Acid pH and Deficient Efflux of Pyrazinoic Acid in Unique Susceptibility of Mycobacterium tuberculosis to Pyrazinamide. J. Bacteriol., 1999, 181, 2044-2049.

[4] BOSHOFF, H. I., MIZRAHI, V., BARRY III., C. E. Effects of Pyrazinamide on Fatty Acid Synthesis by Whole Mycobacterial Cells and Purified Fatty Acid Synthase I. J. Bacteriol., 2002, 184 (8), 2167-2172.

[5] SHI, W., ZHANG, X., JIANG, X., YUAN, H., LEE, J. S., BARRY III., C. E., WANG, H., ZHANG, W., ZHANG, Y. Pyrazinamide Inhibits Trans-Translation in Mycobacterium tuberculosis. Science, 2011, 333, 1630 1632.

[6] DOlezAL, M., CMedlovA, P., PALEK, L., VINSOVA, J., KUNES, J., BUCHTA, V.; JAMPILEK, J., KRALOVA, K. Synthesis and Antimycobacterial Evaluation of Substituted Pyrazinecarboxamides. Eur. J. Med. Chem., 2008, 43, 1105-1113.

[7] DOLEZAL, M. Biologically Active Pyrazines of Natural and Synthetic Origin. Chem. Listy, 2006, 100, 959-966.

[8] CHALUVARAJU, K. C., ISHWAR, B. K. Synthesis and Antimicrobial Activities of Amino Benzylated Mannich Bases of Pyrazinamide. Int. J. Chem. Tech. Research., 2010, 2(3), 1368-1371.

[9] DOLEZAL, M., ZITKO, J., OSICKA, Z., KUNES, J., BUCHTA, V., VEJSOVA, M., DOHNAL, J., JAMPILEK, J., KRALOVA, K. Synthesis, Antimycobacterial, Antifungal and Photosynthesis-inhibiting Activity of Chlorinated N-Phenylpyrazine-2-carboxamides. Molecules, 2010, 15(12), 8567-8581.

[10] WhITEHEAD, R. P., UNGER, J. M., FLAHERTY, L. E., KRAUT, E. H., MILLS, G. M., KLeIN, C. E., CHAPMAN, R. A., DOOLITTLE, G. C., HAMMOND, N., SONDAK, V. K. A Phase II Trial of Pyrazine Diazohydroxide in Patients with Disseminated Malignant Melanoma and no Prior Chemotherapy Southwest Oncology Group Study. Invest. New Drug., 2002, 20(1), 105-111. 
[11] FURUTA, Y., TAKAHASHI, K., FUKUDA, Y., KUNO, M., KAMIYAMA, T., KOZAKI, K., NOMURA, N., EGAWA, H., MINAMI, S., WATANABE, Y., NARITA, H., SHIRAKI, K. In Vitro and In Vivo Activities of AntiInfluenza Virus Compound T-705. Antimicrob. Agents Chemother., 2002, 46(4), 977-981.

[12] A-RAHIM, Y. I., BEYER, K. H. JR., VESELL, E. S. Studies on Pyrazinoylguanidine. 3. Downregulation of Lipolysis in Isolated Adipocytes. Pharmacology, 1996, 53(4), 197-210.

[13] DOLEZAL, M., KRALOVA, K. Synthesis and Evaluation of Pyrazine Derivatives with Herbicidal Activity. In Herbicides, Theory and Applications; Soloneski, S., Larramendy, M.L., Eds.; InTech: Vienna, Austria, 2011, pp. 581-610.

[14] SERVUSOVA, B., EIBINOVA, D, DOLEZAL, M, KUBICEK, V, PATEROVA, P, PESKO M, KRALOVA K. Substituted N-Benzylpyrazine-2-carboxamides: Synthesis and Biological Evaluation. Molecules, 2012, $17,13183-13198$.

[15] JANDOUREK, O., DOLEZAL, M., KLEMENTOVA, M., KRALOVA, K., PESKO, M. Microwave assisted synthesis of new pyrazinamide analogues and their biological evaluation. 16th Int. Electron. Conf. Synth. Org. Chem., 1-30 November 2012; Sciforum Electronic Conferences Series, 2012. [ISSN 3906980-26-X]

[16] DOLEZAL, M., KRALOVA, K., SERSEN, F., MILETIN, M. The site of action of pyrazine-2-carboxylic acids in the photosynthetic apparatus. Folia Pharm. Univ. Carol., 2001, 26, 13-20.

[17] KRALOVA, K., SERSEN F., MILETIN M., DOLEZAL M. Inhibition of photosynthetic electron transport in spinach chloroplasts by 2,6-disubstituted pyridine-4-thiocarboxamides. Chem. Pap., 2002, 56, 214-217.

[18] KRALOVA, K., SERSEN, F., KLIMESOVA, V., WAISSER, K. Effect of 2-alkylthio-4pyridinecarbothioamides on photosynthetic electron transport in spinach chloroplasts. Collect. Czech. Chem. Commun., 1997, 62(3) 516-520.

[19] KRALOVA, K., SERSEN, F., KUBICOVA, L., WAISSER, K. Inhibitory effects of substituted benzanilides on photosynthetic electron transport in spinach chloroplasts. Chem. Pap., 1997, 53, 328331.

[20] NAKAMURA, A., ATAKA, T., SEGAWA, H., TAKEUCHI, Y., TAKEMATSU, T. Studies on herbicidal 2,3dicyanopyrazines. 1. Structure-activity relationship of herbicidal 2,3-dicyano-5-substituted pyrazines. Agric. Biol. Chem., 1983, 47(7) 1555-1560.

[21] NAKAMURA, A., ATAKA, T., SEGAWA, H., TAKEUCHI, Y., TAKEMATSU, T. Studies on herbicidal 2,3dicyanopyrazines. 2. Structure-activity relationships of herbicidal 5-ethylamino- and 5-propylamino2,3-dicyanopyrazines. Agric. Biol. Chem., 1983, 47(7), 1561-1567.

[22] HAYES, B. L. Microwave Synthesis: Chemistry at the Speed of Light; CEM Pub.: Matthews, NC, 2002.

[23] DE LA HOZ, A., DIAZ-ORTIZ, A., MORENO, A. Microwaves in Organic Synthesis. Thermal and Nonthermal Microwave Effects. Chem. Soc. Rev., 2005, 34, 164-178.

[24] JONES, R. N., BARRY, A. L. J. Clin. Microbiol., 1987, 25, 1920. 
[25] National Committee for Clinical Laboratory Standards: Reference Method for Broth Dilution Antifungal Susceptibility Testing of Yeasts: Proposed Standard M 27-P, National Committee for Clinical Laboratory Standards, Villanova, PA, 1992.

[26] KRALOVA, K., SERSEN, F., SIDOOVA, E. Photosynthesis inhibition produced by 2-alkylthio-6-Rbenzothiazoles. Chem. Pap., 1992, 46, 348-350.

[27] MASAROVICOVA, E., KRALOVA, K. Approaches to measuring plant photosynthesis activity. In Handbook of Photosynthesis, 2nd ed.; Pessarakli, M., Ed.; Taylor \& Francis Group: Boca Raton, FL, USA, 2005, pp. 617-656.

[28] JAMPILEK, J., DOLEZAL, M., KUNES, J., SATINSKY, D., RAICH, I. Novel Regioselective Preparation of 5-Chloropyrazine-2-carbonitrile, Pyrazine-2-carboxamide and Coupling Study of Substituted Phenylsulfanylpyrazine-2-carboxylic Acid Derivatives. Curr. Org. Chem., 2005, 9(1), 49-60. 